\title{
ASO Visual Abstract: Oncological Surgery during the COVID-19 pandemic-Effectiveness of Preoperative Screening and Factors Associated with Postoperative SARS-CoV-2 Infection
}

André Lopes, $\mathrm{MD}^{1,2}$ (D) Caroline B. P. Pastore, MD ${ }^{1}$, Paula Deckers, MD $^{1}$, Izabela K. M. W. Halla, MD ${ }^{1}$, Ana Luiza Rezende Dias, MD ${ }^{1}$, Marcos Vinicius Maia da Mata, MD ${ }^{1}$, Adriana do Nascimento Martins, BBiomedSc $^{1}$, Micaela Mazutti Viu, BNS ${ }^{2}$, Rossana Veronica Mendoza Lopez, PhD $^{3}$, and Alayne Domingues Yamada, $\mathrm{MD}^{2}$

${ }^{1}$ Department of Gynecology, São Camilo Oncologia, São Paulo, SP, Brazil; ${ }^{2}$ Nucleo de Pesquisa e Ensino da Rede São Camilo, São Paulo, Brazil; ${ }^{3}$ Oncology Translational Research Center, Instituto do Cancer do Estado de Sao Paulo ICESP, Faculdade de Medicina, Universidade de Sao Paulo, Sao Paulo, SP, Brazil

In-hospital transmission of severe acute respiratory syndrome coronavirus 2 (SARS-CoV-2) may be reduced by routine preoperative screening with a reverse transcriptase-polymerase chain reaction (https://doi.org/10. 1245/s10434-021-11195-4). Length of stay and readmission were correlated with postoperative COVID-19 infection.

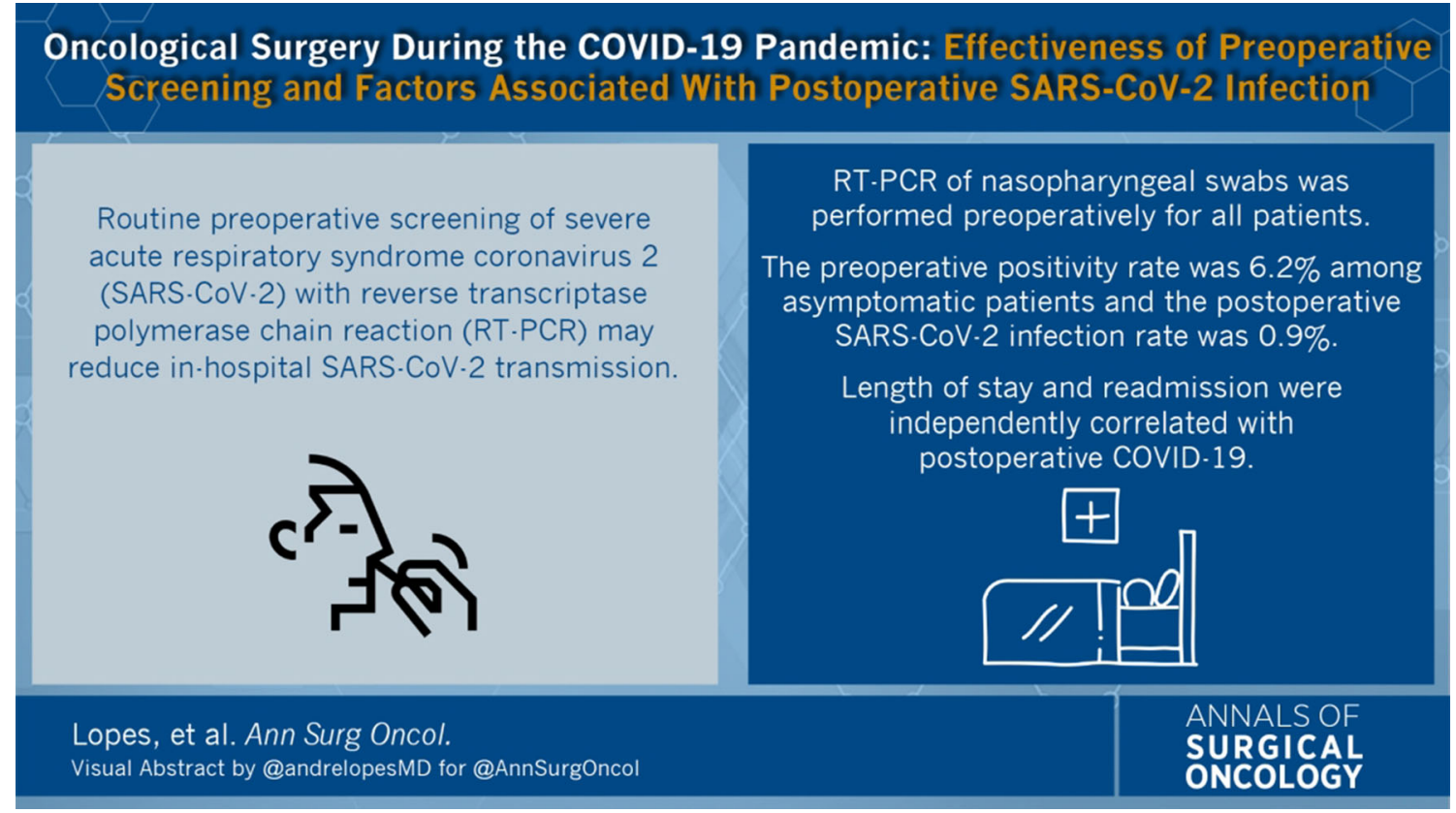

(C) Society of Surgical Oncology 2022
A. Lopes, MD
e-mail: andrelopes.cirurgia@gmail.com

DISCLOSURE There are no conflicts of interest to declare.

Publisher's Note Springer Nature remains neutral with regard to jurisdictional claims in published maps and institutional affiliations. 